\title{
EVALUATING THE VISIBILITY OF MEDIA SENSITIZATION TOWARDS THE UTILIZATION OF MEDIA WEATHER REPORTS AMONG FARMERS IN ANAMBRA STATE
}

\author{
Allen Nnanwuba Adum, PhD \\ Department of Mass Communication, \\ Nnamdi Azikiwe University, \\ Awka, Anambra State, Nigeria. \\ an.adum@unizik.edu.ng
Charles Chukwuemeka Okika
Department of Mass Communication, Nnamdi Azikiwe University, Awka, Anambra State, Nigeria cc.okika@unizik.edu.ng

\section{Chiazor Chiaghana} \\ Department of Mass Communication, \\ Nnamdi Azikiwe University, Awka, \\ Anambra State, Nigeria \\ chiazochiazo@gmail.com

\section{Ogechukwu Okoli} \\ Department of Mass Communication, \\ Nnamdi Azikiwe University, Awka, \\ Anambra State, Nigeria \\ Ogechukwuokoli59@gmail.com
}

\begin{abstract}
The benefits inherent in the utilization of climate change report in Agriculture cannot over emphasized. It helps the farmers to make informed decisions about their plantings and helps improve agricultural proceeds. This study examined the level of exposure of farmers in Anambra state to media weather reports, their dispositions towards the weather reports and their usage of weather reports in farming decision making. This study was designed as a survey. A sample of 400 farmers was drawn from 120000 farmers registered with the Ministry of Agriculture, Anambra State. Six local government areas were selected to represent the three senatorial zones in the state, and four communities to represent the selected local government areas. Findings from the survey indicate that the farmers have knowledge of weather reports but, they do not utilize these because they do not understand the message content and are unable to interpret it towards utilizing them in making decision for their planting system. The study concluded that difficulty in understanding of the weather reports and religious belief were the factors that inhibit the use of weather reports in farming decision making among farmers in Anambra State. The study recommended, increased and sustained aggressive sensitization should be done by the media. The study recommended that the bodies responsible for preparing the weather forecast like the Nigerian Meteorological Agency should be providing regular and updated weather reports to the media and make such reports to be less technical in order to bridge the challenge of difficulty in understanding.
\end{abstract}

Keywords: Weather reports; Sensitization; media; farming decision making; application of weather reports;

\section{INTRODUCTION}

Climate is a primary factor in agricultural production in Nigeria. The economy and food supply are closely linked to climate. Fluctuations in the climatic conditions can exert serious pressure on the agricultural systems, patterns of production, productivity and income. Thus, farmers are contending with variations in climate and achievement of optimum yield so as to 
DOI: $\underline{\text { doi.org/10.47851/naujocommed.v2i1.108 }}$

secure a suitable farm output for increased food supply. This has a bearing on the output and productivity of these farmers (Meza, Hansen, \& Osgood, 2008).

Apparently, in the Eastern Part of the country, the issue of weather report utilization has been a dominant one, despite its being perceived as a positive factor to a successful planting system. Farmers who are supposed to be knowledgeable of its importance tend not to apply it in their planting system; perceptively as a result of poor decoding of information. Favorable weather is one of the major prerequisites for enhancing agricultural productivity. This, however, is often least guaranteed by farm households at the onset of every production season by the media. Obviously, agricultural production potentials of the state are currently facing severe constraints from unexpected weather conditions, many of which had led to unquantifiable farm production losses.

Over the years, pronounced droughts, reduction in volume of rainfall, excessive rainfall leading to flooding, too high and or low temperature, among others had been reported in many areas of the Anambra State. Inability to perfectly understand future weather conditions often exposes the farmers in Anambra State to several production uncertainties which could necessitate adoption of some conservative approaches that sacrifice potential farm productivity through some risk minimization decisions. The premise for promoting sustainable agricultural development in the state is now anchored on ability to perfectly predict some weather parameters, along with many other environment-related production constraints.

The past few decades have witnessed growing interest in the mechanisms for ensuring delivery of weather forecasts in a manner that ensures wider coverage and minimizes utilization risk. Provision of accurate seasonal weather forecasts is a way of enhancing farm households' preparedness and their coping ability with adverse weather situations in order to reduce associated welfare losses. Due to its substantial vulnerability to weather vagaries, rain-fed agriculture which is mostly practiced in the state can substantially benefit from seasonal weather forecasts. Some evidence abounds on the impact of weather forecasts. Although the media provides weather forecast services in order to reduce farm production losses resulting from weather issues, access and utilization pose some challenges.

Most farmers are perceived as illiterate, because of this, they often find it difficult, seeking information through either the newspaper or even the television. Some find it difficult to interpret what the forecast contains or they do not have those media to access the information if any is given through the mass media (Klopper, Vogel \& Landman, 2006).

Ozor \& Nwankwo (2008) aptly points out possible reasons for the minimal view and use of weather report, especially in a predominately business area, like Anambra state; People feel so busy and do not devote time towards watching or viewing the weather forecast, some of them who do so, do not properly decode and understand the weather report primarily due to its technicalities, and secondly by low sensitization from the media to farmers, either through programmes or publicity on the importance and benefits of utilizing the weather forecast in their planting system and also teaching them what the weather forecast entails .

Most times, the media rarely airs weather reportand this leads to a dwindling of interest of a few who watches it. The media is an institution that has traditional obligation to educates, informs and also entertains, are supposed to educate their public through programmes or publicity on any information or message that seems difficult to comprehend especially issues 
DOI: doi.org/10.47851/naujocommed.v2i1.108

like the technicalities in weather report and also on the importance of its application by farmers.

\section{STATEMENT OF PROBLEM}

It has been observed that weather forecast is not only farmers in making planting decisions but it also to every individual, because it helps one to have a good plan of the outfit to wear and where to be at a particular point in time especially during the raining seasons.

Anambra state is one of the cities in Nigeria where farmers have experience heavy loss of farm produce due to flood orchestrated by change in climate. This normally occurs between May to October annually. That is why weather report which comes as a result of these changes in climate plays an important role in the growth and development of plants in general and crops in particular.

Knowledge of impending weather condition will help in the identification of crop varieties that will perform well in a particular growing season by the farmers. The mass media which is responsible for educating and informing the public, may or may not have been issuing seasonal weather report for some time now and it is important to establish if the information has be appropriately used by the farmers or not and if not, then why not.

In the light of the foregoing, evaluating the visibility of media sensitization towards the usage of weather reports among farmers in Anambra becomes imperative. Are these reports available to farmers in Anambra state? To what extent are these farmers exposed to media weather reports? Is there mitigation vis-à-vis understanding and usage?

\section{Purpose/Objective of the study}

This study evaluated the visibility of media sanitization towards the utilization of media weather report among farmers in Anambra state. However, the specific objectives are:

1. Determine the number of farmers in Anambra state that have access to weather report.

2. Find out the sources of weather report available to farmers in Anambra state.

3. Examine the disposition of farmers to weather report in Anambra State.

4. To ascertain the extent to which farmers utilize weather report available to them.

\section{Research Questions}

Based on the foregoing objectives, the following research questions were formulated to proffer solutions to the problem of this study;

i. What numbers of farmers in Anambra State have access to weather report?

ii. What are the sources of weather reports available to farmers in Anambra State?

iii. What is the disposition of farmers in Anambra state to weather report?

iv. To what the extent do farmers utilize weather report available to them?

\section{WEATHER FORECASTING}

Weather forecasting is the predictions of changes on earth's surface caused by atmospheric conditions example, snow, ice cover, storm tides and floods to determine how the atmosphere evolves in future. It is also the application of science and technology to predict the conditions of the atmosphere for given location and time.

In early years when humans were still inhabitants from the caves, they were able to direct nature's signs that is the change in weather and uptill recent time, weather forecasting is stil 
DOI: doi.org/10.47851/naujocommed.v2i1.108

carried out the same method as it was by the earliest humans. Although seemingly quite different there are underlying similarities between both practices. In each case the forecaster asks "what is?" in the sense of "what kind of weather prevails today?" and then seeks to determine how it will change in order to extrapolate what it will be. Cahir (2021)

Weather records were kept mainly from those who are engaged in Agriculture. Agriculturist's planting and harvesting can be planned efficiently if weather patterns can be estimated. Weather forecasting is vital to different relevant fields that use climate change for their activity's fields like the aviation, food companies, commodity traders. Weather forecasting determines the condition of the weather.

\section{WEATHER REPORTS AND AGRICULTURE}

Weather reports or forecast has significant roles it plays in the field of Agriculture. Crops are produced efficiently when details of weather information are made known.

Farmers make their decisions on how to plant their crops based on weather condition's information. Eiltis(2018). Eiltis stated that there are primary areas of farming that are fundamentally affected impact by weather. Weather plays an important role in Agricultural production. It has a profound interest on crop growth, development and yields on the incidence of pests and diseases on water needs and on fertilizer requirements. Weather aberrations may cause physical damage to crops and soil erosion. Dyes D.F, Hansen W.J, Mariani Luigi (2010).

The optimal growth of crops is determined by weather factors and weather events on crops build up slowly but are often widespread enough to destabilize national agricultural production. In order to achieve effective production in Agriculture, weather forecasts must be timely and accurate and areas to which the weather forecast will be applicable must be unambiguously stated.

The positive effect of weather forecasts in agriculture is maximized if weather forecasters are aware of the farmers' requirements and farmers know how to make the most use of th $\mathrm{e}$ forecasts that are available (Deyes D.F et al). Forecast weather information can help farmers better understand and track the growth status/ stage to make informed decisions.

\section{MEDIA AND PUBLIC KNOWLEDGE OF WEATHER REPORT}

According to Low (2000), information is a means of transferring events for better awareness to add new meaning that could change events, lives, or experiences, awareness and use of information produce knowledge. The ever-increasing information explosion on agricultural produce: Seedling, harvesting, marketing and storage among others may have considerable implications on farmers, implementation of farm tools and the extension services, (Oto, 2011, Ovwigho, 2009). Report has it that dissemination of adequate information literacy to the grass root especially to farmers will enhance productivity. Mosser (2007) observes that the "need for effectivecommunication, farmers outreach and sensitization to increase forecast utilization, collective action and behavior change is ever present, and is perhaps most pressing in the context of anthropogenic climate change". The challenges associated with communicating climate change in order to facilitate societal response are enormous.

The importance of famers' information literacy and awareness towards agricultural produce and food security and climate change cannot be over-emphasized.( Sokoya et al, 2012) observed that interpersonal connectivity between farmers and agricultural extension agents will enhance farmers' information literacy, knowledge and awareness of current climate 
DOI: $\underline{\text { doi.org/10.47851/naujocommed.v2i1.108 }}$

forecast and trend in farming will boost stages of faming and abundance food supply. The importance of farmers' information literacy cannot be over emphasized as they produce what the nation needs to feed her populace all year round.

There has always being contributions from research results on how agricultural production can be increased through application of weather information and forecast. According to (Olowu, 2008), such research results include high yielding breeds of animal, disease resistant breed of seeds and seedlings, mechanized farming and different storage means which famers must know to improve productivity and increase food security. Farmers' information literacy in this study is seen as the farmers' ability to critically think and determine the extent of his information need and be able to access available information effectively and efficiently and evaluate the information to accomplish a specific purpose in farming. Different definitions are given to information literacy depending on the concept of the study, American Library Association (1995) expressed that "To be information literate, a person must be able to recognize when information is given and have the ability to locate, evaluate, and use effectively the disseminated information" Therefore information literate people are those who have learned how to learn, having the ability and skilled in critical thinking; to be information literate is a lifelong learning.

Studies have shown that the public learns a large amount about science through consuming mass media news. The media can play a crucial role in disseminating useful climate information to effectively guide public debate and understanding about the weather, climate and climate change. Millions of farmers are grappling with the changing climate around them but are starved of real timely information on what their options are. Still, it is not uncommon to hear them talking about it in markets, homes and communities (Olarewaju 2011).

Various studies have established that farmers understanding of weather report and climate change related issues, including the negative effect of the fast-changing climate on lives are low. There have been calls to the media to step up their reportage of the weather report and climate change issues in order to create the necessary awareness and importance of it. Therefore, the role of the media should not be to simply report weather or even climate change events and disasters. The media have a role in influencing personal, national and international action to address weather report. The reportage should set agenda on what people should know and do (Nwabueze, 2007).

Boykoff and Rajan (2007) have also observed that journalism shapes public concern. This is not to disregard the fact that the media are not the only factors that shape public understanding of given issues as exposed in the media effects debate over the years. The media are a chief part of social communication process. Not only do people receive information directly from the mass media, they also discuss such information in conversations and pass on news and interpretations in a process of diffusion. Thus in a media saturated society, exposure to mass communication plays a singularly important part in forming our habits of perception and interpretation of the world .In this significant way the media's portrayal of reality can indirectly, but strongly influence people's behavior.

Nigeria experiences both dry and rainy season, these two seasons come with terrible heat and horrible rainfall that obstruct people's movement. Too much heat damages crops and vegetation while too much rainfall causes widespread flooding causing some households to relocate .Weather-related calamities have become a yearly occurrence for which people have 
DOI: doi.org/10.47851/naujocommed.v2i1.108

not learned to prepare for .Scientific findings reveal that changes in weather conditions have and will continue to have a major impact on human life and ecosystem. Rising temperature, floods, droughts and heavy precipitation can lead to severe problems such as increased diarrhea, malnutrition and malaria. Floods and rising sea levels can cause injuries, drowning, severe physical and mental trauma, particularly for citizens who live along major river areas or islands and in low-lying coastal areas. In Agriculture, heavy rainfall has caused erosion, irrigation, which leads to loss of plants and crops and in turn brings about food shortage.

Many Nigerians are aware that some changes occur in the environment year in and year out but lack knowledge of the reasons for such change.They are also aware of increased disease, food shortages and extreme flooding at various localities during certain periods of the year. Yet there have been no efforts to reduce the occurrences or avert them altogether.There is a need to educate the farmers of the signs of climate change and what weather report is all about. Many people are aware that climate change is severely affecting livelihoods in Nigeria through changes in rainfall patterns. About seventy percent of the farmers interviewed expressed that their crops were washed away by floods, eliminating their yields for consumption and for sale as well.

For many years, researchers have explored local knowledge about environmental change and increasingly over the past decade, local knowledge in relation to climate change specifically. They know how much more about the content of the different types of knowledge that are important for responding to climate change from modeling future rainfall changes in a particular country to how to get the most out of an agricultural environment in highly variable conditions. However, they still do not know how to translate these different forms of knowledge into practice and make them accessible to policy makers, front-line staff (such as agricultural extension officers or health workers) and people in poor communities on the ground.

\section{THEORETICAL FRAMEWORK}

This work is hinged on the Agenda Setting theory and the knowledge gap theory. The Agenda Setting theorywas officially developed by McCombs and Shaw in their study in 1972. The theory posits how the mass media helps to raise certain issues and make them public agenda. According to Littlejohn and Foss (2009) the theory expounds the interconnectivity between the weight the media exacts on an issue and the audience's reaction or opinion. Some core assumptions regarding agenda setting theory are;

i. the media does not just make the members of the audience aware of certain issues but they help them to know how important such issues are.

ii. The media does this by frequent reporting of such issues

iii. The prominence given to such reports.

In relation to the study, Rogers and Dearing (1988) believes that the Agenda setting theory should not be limited to forming public opinion as regards elections, but should also include other issues that the reality of the world offers; such issues like climate change, natural disasters.

Therefore, since the mass media is presumed to have power to pre- determine issues that the audience should be aware of in the society, the mass media; through their presentations of events or reportage of news, can place prominence on weather reportage, thereby making 
DOI: doi.org/10.47851/naujocommed.v2i1.108

farmers in Anambra State to see weather reports as important and also be informed on the benefits accrued from utilizing the report especially in making agricultural decisions.

The knowledge gap theory was first proposed by researchers, Tichenor Phlip, Donohue George and Olien Clarice in 1970. The principles of this theory focus on how knowledge is distributed in the society and the role of the mass media in the distribution. Theory portrays the disparity created by the way media messages are infused into the society between the higher socioeconomic class and the lower socioeconomic class.

Agreeing to this, Okenwa (2002) posits that the media have added so greatly to the flow of public information that they would have helped to modify the differences of knowledge resulting in inequalities of education and social position. This means that people with higher educational background and social relationships, have the tendency of developing better communicative skill, better chances of being exposed and access to broader issues that affect the society, and a greater amount of stored information than the less educated.

In view of this work, farmers in Anambra state who are perceived to be less educated may not have access to or be exposed to such information from the media like the weather forecast due to this gap in knowledge and if they are, might not have the ability to understand the technicalities in the report as their counterpart that are educated.

Tichenor et al, (1970) as quoted by Tran (2013) affirms to this by stating three media related factors that caused this gap in knowledge. They are;

i. Segments of the population are different in ability to process, integrate and interpret information.

ii. There is a difference between social classes in selective use, acceptance and retention of information from the mass media.

iii. The structure of the mass media appears to make information more accessible to an affluent audience.

\section{METHODOLOGY}

This study was designed as a survey. The study area was Anambra state with a focus on commercial farmers. Registered farmers in Anambra State, about 120000 (Ministry of agriculture) made up the population of this study. The 400sample size was statistically determined using the Taro Yamane formula thus:

$\mathbf{n}=\frac{\mathbf{N}}{\mathbf{1}+\mathbf{N}(\mathbf{e})^{2}}$

Where: $\quad \mathrm{n}=$ Sample Size

$$
\begin{array}{lll}
\mathbf{N} & = & \text { Total Population of Study } \\
\mathbf{1} & = & \text { Constant Variable } \\
\mathbf{e} & = & \text { Accepted Sampling Error }(\mathbf{0 . 0 5})^{2}
\end{array}
$$

$* 95 \%$ confidence level and $\mathrm{p}=0.5$ are assumed.

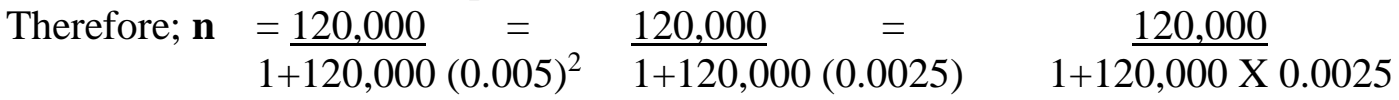

$$
\begin{aligned}
& \frac{120,000}{120,000} \times 0.0025=\frac{120,000}{301}=\mathbf{3 9 8 . 6 7}=\quad \text { approximately (400) }
\end{aligned}
$$

The multi-stage sampling technique was used At the first stage, 21 LGAs in Anambra state were divided into groups or clusters according to the three senatorial zones with each cluster 
DOI: doi.org/10.47851/naujocommed.v2i1.108

containing seven of local governments. To ensure that every farmer within the local government in the clusters had equal chance of being sampled, a simple random sampling technique adopted, using a "Statistical Random Numbers Table". Randomly, each group in the population of study was assigned a number. From the numbers in the random numbers table, two local governments from each senatorial zone were randomly chosen. Using the same random number table, two communities were randomly chosen from the Local governments.

\begin{tabular}{|l|l|l|}
\hline Groups & LGAs & Communities \\
\hline $\begin{array}{l}\text { Anambra Central Senatorial } \\
\text { Zone }\end{array}$ & Njikoka and & $\begin{array}{l}\text { Enugwu-Agidi and Abagana } \\
\text { Communities } \\
\text { Adazi-Nnukwu Community } \\
\text { and Neni Community. }\end{array}$ \\
\hline $\begin{array}{l}\text { Anambra South Senatorial } \\
\text { Zone }\end{array}$ & $\begin{array}{l}\text { Orumba and } \\
\text { Aguata }\end{array}$ & $\begin{array}{l}\text { Umunze and Umuomaka } \\
\text { community } \\
\text { Igboukwu and Umuchu. }\end{array}$ \\
\hline $\begin{array}{l}\text { Anambra North Senatorial } \\
\text { Zone }\end{array}$ & $\begin{array}{l}\text { Anambra west and } \\
\text { Ogbaru }\end{array}$ & $\begin{array}{l}\text { Anam. Community and Ifite - } \\
\text { Atani community and Amiyi. }\end{array}$ \\
\hline
\end{tabular}

Also, from the selected communities, four villages were randomly selected to represent the communities, this was done the same the communities were selected.

- $\quad$ Enugwu-Agidi- Achala, Egbedeamu, Ifite and Irunebo.

- Abagana- Agagbo-Abagana, Adagbo- orafia, Adagbo-Umuduna, Akpu-

Abagana.

- Nzam- Anakpa,Atakol, Aza, Igeja

- Ifite-Anam Abegbu, Iyiora Anam, Mmiata, Umundeze -Mmiata.

- Umunze Amuda, Ozara, Umuizo, Abaha.

- Umuomaku Ndiocha, Okpobe, Umuokpurukpu, Umunambu.

In distributing the questionnaire, the researcher used aNon- Probability Convenience Sampling, whereby copies of the questionnaire were served only on respondents who were available at the time and showed willingness to be sampled, when the researcher visited each of the chosen villages. Questionnaire (open-ended and closed-ended) was used as the instrument for data collection. This means that out of the 400 copies of questionnaires structured and distributed, each of the 25 villages representing the three senatorial zones, got 16 questionnaires for 16 respondents. Data gathered were presented and analyzed using SPSS 19 data analysis software.

\section{DATA PRESENTATION AND ANALYSIS}

Findings from this study were drawn from data obtained from 400 residents of Awka Urban.

\section{Demographic Data}

Data from 400 farmers in Anambra State show that59\% of the total sampled were female, representing over half of the total sample while that of the male was $41 \%$. This shows that majority of sampled respondents were female. Also, $42 \%$ falls within the age bracket of $25-$ 39. Those within the age brackets of 40-49 account for $38 \%$, and those within the age of 50 
DOI: doi.org/10.47851/naujocommed.v2i1.108

constituted $18 \%$ of the respondents. While a significant few, $1.5 \%$ of the respondents did not indicate their age. Results, also, that $26 \%$ of the respondents were Primary School holders; $28 \%$ secondary school holders; $21 \%$ of were above secondary school level while another $21 \%$ of the respondents were not educated. More than half of the respondents were married, while a significant few, $8 \%$ of the respondents were single.

\section{Respondents' farming experience farm crop type}

Data in Table 1 show the respondents' farming experience.

Table 1: Respondents' Farming Experience

\begin{tabular}{lll}
\hline Variable & Frequency & Percent \\
\hline $1-5$ Years & 64 & 16 \\
& & \\
$10-15$ & 288 & 72 \\
15 and above & 48 & 12 \\
Total & 400 & 100 \\
\hline
\end{tabular}

A greater percentage of the farmers have had upwards of 15 years' experience. This suggests that farming appears the mainstay in the economy of the study area.

\section{Respondents' exposure to weather reports}

The data in Table 2 show respondents' exposure to weather reports.

Table 2: Exposureto weather report

\begin{tabular}{lll}
\hline Variable & Frequency & Percent \\
\hline Yes & 368 & 92 \\
No & 28 & 7 \\
No response & 4 & 1 \\
Total & 400 & 100 \\
\hline
\end{tabular}

Responses to Table 2 show a high level of exposure to weather report among the respondents; $92 \%$ among them affirmed their exposure to weather reports, while $7 \%$ indicated that they were not exposed to weather reports. One percent did not respond to the question. This goes to show that majority of Farmers in Anambra State are exposed to Weather Reports.

Table 3: Frequency of Exposure to Weather Report

\begin{tabular}{lcc}
\hline Variables & Frequency & Percent \\
Always & 216 & 54 \\
Sometimes & 96 & 24 \\
Rarely & 88 & 22 \\
Total & 400 & 100 \\
\hline
\end{tabular}

Data in Table 3 show that $54 \%$ of respondents are always exposed to Weather reports, $24 \%$ are sometimes exposed to it, while $22 \%$ are rarely exposed to it. These data indicate that majority $(78 \%)$ of the respondents are either always or sometimes exposed to weather reports as against the minority (22\%) that are rarely exposed to it. 
Volume 2 Number 1 Jan-Mar Issue

DOI: $\underline{\text { doi.org/10.47851/naujocommed.v2i1.108 }}$

Table : Respondents' Major Sources of Weather Reports

\begin{tabular}{lcc}
\hline Variables & Frequency & Percent \\
Radio & 136 & 34 \\
Television & 100 & 25 \\
Newspaper & 64 & 16 \\
Magazine & 48 & 12 \\
Android phone & 20 & 5 \\
No response & 32 & 8 \\
Total & 400 & 100 \\
\hline
\end{tabular}

Responses to table 4 indicates that $34 \%$ of the respondents have Radio as their major source of weather report, $25 \%$ have Television, $16 \%$ have newspaper, $12 \%$ have magazine, $5 \%$ have Android phone while $8 \%$ did not respond. Thus, this shows that Radio is the major source of getting weather reports, seconded by Television by the farmers more than any other sources. And this can be attributed the portability of Radio.

Table 5: Conscious Consultation of Source of Report

\begin{tabular}{lcc}
\hline Variables & Frequency & Percent \\
Often & 60 & 15 \\
Occasionally & 132 & 33 \\
Rarely & 208 & 52 \\
Total & 400 & 100 \\
\hline
\end{tabular}

Table 5 indicates that $15 \%$ of the respondents consciously consult their source of weather report always, $33 \%$ occasionally consult this, while $52 \%$ rarely do this. Hence, while roughly half of the respondents make conscious effort to consult their weather report source either often or occasionally, half of them do this rarely.

Table 6Respondents' understanding of weather reports

\begin{tabular}{lll}
\hline Variables & Frequency & Percent \\
\hline To a large extent & 20 & 5 \\
To some extent & 32 & 8 \\
To a little extent & 348 & 87 \\
Total & 400 & 100 \\
\hline
\end{tabular}

Data in Table 6 show that about $5 \%$ of the population understands the content of weather report to large extent, $8 \%$ understands it to some extent while a greater percentage, $87 \%$ understands it to a little extent. This goes to show that more than half of the farmers do not understand the weather report.

Table 7: Respondents' Belief of Weather Report

\begin{tabular}{lll}
\hline Variables & Frequency & Percent \\
\hline To a large extent & 28 & 7 \\
To some extent & 72 & 18 \\
\hline & & \\
& & \\
& &
\end{tabular}


Volume 2 Number 1 Jan-Mar Issue

To a little extent

300

75

Total

400

100

Data in Table 7 shows that $7 \%$ of the respondents believe to a large extent weather report, $18 \%$ believe this to some extent, while $75 \%$ believe the information to a little extent. This implies that majority of the farmers $(75 \%)$ do not believe such report.

Table 8: Extent of Utilisation of Weather Reports

\begin{tabular}{lll}
\hline \multicolumn{1}{c}{ Variables } & Frequency & Percentage \\
\hline Regularly & Nil & Nil \\
Occasionally & 4 & 1 \\
Rarely & 48 & 12 \\
Never & 348 & 87 \\
Total & 400 & 100 \\
\hline
\end{tabular}

Data in table 8 show that $87 \%$ of the respondents never utilized weather reports in making farming decisions, $12 \%$ rarely do while $1 \%$ of the respondents occasionally do. This corelates with the findings in Table 6, suggesting that the farmers, mainly, did not believe in the weather reports which may be an influence in their not basing their farming decisions on weather reports.

Table 9: Major Constraints to Utilisation of weather report

\begin{tabular}{lll}
\hline Variables & Frequency & Percent \\
\hline Difficulty in understanding & 280 & 70 \\
Difficulty in Access & 20 & 5 \\
Religious beliefs & 60 & 15 \\
Lack of personal & 40 & 10 \\
commitment & & \\
Total & 400 & 100 \\
\hline
\end{tabular}

Data in Table 9show that $70 \%$ of the respondents have difficulty of understanding as their major constraint to utilization of weather report, $20 \%$ have difficulty in access as theirs, $60 \%$ have religious beliefs as theirs, while $40 \%$ have lack of personal commitment as their main obstacle to use of weather report. Thus, difficulty of understanding stands out as the most important factor working against the respondents' utilization of weather report.

\section{ANALYSIS OF RESEARCH QUESTIONS}


The first research question seeks to find out the number of farmers in Anambra statewho have access to weather reports. To answer this question, the researcher referred to Tables 2 and 3above. Data in Table 2 shows that the majority of the respondents have been exposed to weather reports. Furthermore, data in Table 3 indicate that majority $(78 \%)$ of the respondents are either always or sometimes exposed to weather reports as against the minority (22\%) that are rarely exposed to it. Based on the foregoing, it is admitted in answer to the first research question that there is widespread access to weather reports by the farmers in Anambra state.

The second research question sought to discover the sources of weather reports available to farmers in Anambra State. Data in Table 4 indicate that Radio (34\%) featured most as the major source of weather forecast among the respondents, while the Television (25\%) came second followed by newspaper and magazine. Therefore, it could be stated, in answer to the second research question, that Radio and the Television are the most prominent sources of weather reports among farmers in Anambra State.

The third research question sought to find out the disposition of farmers to weather reports. Data in Table 6 show that only a minority (5\%) admitted that their understanding of weather report is "to a large extent", suggesting that there is a high rate of lack of understanding of the weather reports amongst the respondents. Similarly, Table 7 shows that majority $(83 \%)$ believe the weather report either to a little or some extent as against the minority (7\%) who believe it to a large extent. Consequently, it may be admitted, in answer to the third research question, that farmers in Anambra Statedo not understand and believe such reports.

The fourth research question intends to understand the extent Farmers utilize weather reports. Data in Table 8 data indicate that the majority $(87 \%)$ of the respondents do not use the weather reports they access, while a minority (13\%) utilize such information either rarely or occasionally. Lastly, table9 shows that difficulty $(70 \%)$ stands out as the most important factor working against the respondents' utilization of weather reports followed by religious belief. Consequent on the foregoing, it may be stated, in answer to the fourth research question, that there is a low rate of use of weather reports among farmers in Anambra State and that lack of difficulty in understanding is the major constraint to their utilization of weather reports.

\section{DISCUSSION, CONCLUSION AND RECOMMENDATIONS}

The first finding of this study indicates that there is widespread access to weather reports among farmers in Anambra State; the second finding reveals that Radio and Television are the most prominent sources of weather reports among thesefarmers. The implication of the foregoing is that weather report has become readily available to this group; a reflection of the agenda theory that says that the mass media helps to raise certain issues and make them public agenda.

Similarly, just as Rogers and Dearing (1988) posits that the mass media should not be limited to only setting agenda as it concerns politics but should report other realitiesthat the world offers; such issues like climate change, natural disasters. The mass media according to the findings from this study are playing this role effectively. 
The third finding of the research holds that farmers in Anambra State largely do notunderstand and believe such reports. And this could be traced to lack of information literacy on the part of the farmers which is widened by the media their reportage of weather report. According to the principles of the knowledge gap theory, that the media through the use of technicalities in reporting weather has created a gap, which made weather reports to be understood by only the educated leaving out the uneducated which the farmers are perceived to be.As aptly captured by Klopper et al (2007) that Most farmers are perceived as illiterate, because of this, they often find it difficult, seeking and understand information through either the newspaper or even the television. This Sokoya et al (2012) added that in order to achieve farmers' information literacy and close the gap in knowledge, there should be increased interpersonal connectivity between farmers and agricultural extension agents which the media is one of them.

The fourth finding states that there is a low rate of use of weather report among farmers in Anambra State, and the major constraints to their utilization of weather report are difficulty in understanding and religious belief. This could be linked to the third finding that farmers do not understand and believe the reports, hence, there is low usage of the report especially in making planting decision. And according to the observations of Mosser (2007) that the "need for effective communication, farmers outreach and sensitization to increase forecast utilization, collective action and behavior change is ever present, and is perhaps most pressing in the context of anthropogenic climate change". This is also in line with the tenets of agenda setting theory as captured by Nwabueze (2007) that in the reportage of weather forecast, the media should set agenda on what people should know and do.

This study concludes that there is some level of visibility of media sensitization towards the utilization of weather reports among farmers in Anambra State. Difficulty in understanding and improper decoding of the reports due to technicalities and religious belief has posed a challenge to the utilization of the report by the farmers. Therefore, there is need for the media to re-strategize on how to report weather bridging the gap created by their reportage and more radical approaches should be employed which should targeted at farmers at the grassroot level towards benefits of utilization of weather reports among farmers in Anambra State. Just as Uwakwe (2016) suggested that the use of radio and television drama, documentaries, talkshows, posters, billboards, adverts, participatory interpersonal communication and development news, as dialogical instruments for change, should be paramount.

Thus, the study recommends as follows;

i. Since the study found radio and television as some of the leading sources of weather forecast in Anambra State, aggressive regularsensitization should be done by the media using these two sources especially the radio as a way of further exploring this effective platform.

ii. Similarly, bodies responsible for preparing the weather forecast like the Nigeria metrological Agency should be providing regular and updated weather reports to the media. And also making the report to be less technical in order to bridge the challenge of difficulty in understanding.

iii. The media should collaborate with the Agencies in charge of weather forecast and Ministry of Agriculture to be regularly organizing grassroot awareness programme for farmers in Anambra State on the benefits of utilizing weather reports in planting decisions.

iv. The multi-media approach should be adopted for dissemination of weather report to farmers in Anambra State. This strategy will ensure that all and sundry are reached 
DOI: doi.org/10.47851/naujocommed.v2i1.108

irrespective of one's media preferences and access restriction.

v. The State government through the Ministry of Agriculture should ensure that farmers in all the local government areas are aware of what the weather holds for them before every planting season starts. Similarly, plans should be made to improve the encoding of weather reports for famers

\section{REFERENCE}

American Library Association, 1995.

Boykoff, M. and Rajan, .S. (2007). Signals and noise: Mass media coverage of climate change in the USA and the UK. EMBO reports 8, 3, 207.

Deyes, F.J.,Anice, G.,James,W.\& Luigi, M. (2010). Weather and Climate forecasts for Agriculture. In H.P. Das \& K. Stigter (Eds). Climate Change for Agriculture. Retrieved from http://www.agrometerology.org.

Cahir,J.J. (2021). Weather Forecasting. The Encyclopedia of Pennsylvania State. Retrieved fromhttps://www.britannica.com

Klopper, E., Vogel, C.H., Landman, W.A.(2006). Seasonal climate forecasts - Potential Agricultural-risk management tools? Climatic Change 76, 73-90.

LittleJohn, S.W. and Foss, K.A. (Ed.) (2009). Encyclopedia of Communication theories. Vol.1 Retrieved from http://dx.doi.org/10.4135/9781412959384

Low, .L. (2000,). Economics of information technology and the media Singapore: [Paper Presented at the Seventh International LL in E.

Meza, .F.J., Hansen, J.W., Osgood, D., (2008). Economic value of seasonal climate forecasts for agriculture: review of ex-ante assessments and recommendations for future research.

Elits, M. (2018). The Role of Weather and Weather forecasting in Agriculture. Retrieved from https://www.dtn.com.

Moser, S.C. and Dilling, L.(eds) (2007)., Creating a Climate for Change: Communicating Climate Change and Facilitating Social Change. Cambridge: Cambridge University Press.pp.549

Nwabueze, C. (2007). Environmental communication: Perspectives on green communication and information management. Enugu: Daisy

Olarewaju, .A. (2011) Media audience awareness of the implications of climate change MA project, Department of Mass Communication, University of Nsukka.

Olowu, .T. A. (2011) Assessment of Agricultural Information Needs For CTA's Product and Service in Africa, Caribbean and Pacific (ACP) State - Country Study; Nigeria. 
Oto, J. O. \& Shimayohol, .D. (2011) Extension communication channels' usage and preference by farmers in Benue State, [Nigeria, Journal of Agricultural Extension and Rural Development Vol. 3(5), pp. 88-94

Ozor, .N. \& Nwankwo, .N. (2008). The Role of Local Leaders in Community Development Programmes in Ideato Local Government Area of Imo State:Implication for Extension Policy, Journal of Agricultural Extension, 12 (2): 63-75.

Rogers, E.M. and Dearing, J.W. (1988). Agenda Setting Research: where has it been, where is it going? Communication year book II,55 -594.

Sokoya, . A .A , Onifade, F..N and Alabi, A.O. (2012, Aug) Establishing Connections and Networking: The Role of Social Media in Agricultural Research in Nigeria.

Trans, H. (2013). Does Exposure to online media matter? The Knowledge gap and the mediating role of news use. International Journal of Communication. 7(2013), 831852. Retrieved from https://www.researchgate.net.

Uwakwe, O. (2016). "Gully Erosion in Anambra State: Remedial Measures \& MediaInterventionism”. Oko Journal of Communication and Information Sciences. Vol. 2, No.1, 38-48. 